\title{
EDITORIAL
}

\section{The European Respiratory Journal makes COPD a priority}

\author{
J.B. Soriano*, V. Brusasco\# and A.T. Dinh-Xuan ${ }^{\star}$
}

27 hronic obstructive pulmonary disease (COPD) represents a major problem for public health worldwide and its burden is expected to increase in the next decade. Despite the extensive resources invested in research and the wealth of studies published in leading scientific journals, there are still many unknown aspects regarding the nature of COPD, which make this disease difficult to treat. A number of authors and societies have recently outlined some of the burning questions on COPD that need to be addressed by researchers in order to reduce the burden of the disease and help funding agencies to prioritise limited resources in competitive calls. They include documents from the American Thoracic Society (ATS)/European Respiratory Society (ERS) [1, 2], the Global Alliance against Chronic Respiratory Diseases (GARD) [3], the International Primary Care Research Group [4] and the American Journal of Respiratory and Critical Care Medicine [5, 6].

The number of indexed respiratory journals has substantially increased in the past few years and some also incorporate COPD in their title, which allows more room for articles on this disease. The European Respiratory Journal (ERJ) has already published many papers on COPD and is eager to publish more, and better, research on this topic in the near future. However, we must keep in mind that space is limited and the competition for priority is tough among manuscripts in different fields. The ERJ can currently accept less than $15 \%$ of submitted manuscripts, and immediate rejection without external peer review is becoming a painful but necessary measure given the overload of manuscripts not focused on sufficiently relevant questions. We understand that, after the time-consuming task of formatting text, tables and figures, collecting signed forms, and then uploading it all in a web server, no one enjoys a same-day response of "No thanks".

In this editorial we highlight some topics and questions we consider of the highest relevance in COPD research and worth the utmost consideration by the ERJ editorial team. Needless to say that scientific merit remains the fundamental determinant of the final accept or reject decision in any given submission $[7,8]$. We hope that helping future authors to direct their manuscripts to these topics will ultimately produce the mutual benefit to

\footnotetext{
*Fundación Caubet-CIMERA Illes Balears, Bunyola, Islas Baleares, Spain. "Dept of Internal Medicine, Medical School, University of Genoa, Genoa, Italy. "Dept of Cardiopulmonary Medicine, Cochin Hospital, University Paris Descartes, Paris, France.

CORRESPONDENCE: J.B. Soriano, Programa de Epidemiología e Investigación Clínica. Fundación Caubet-CIMERA IIles Balears, Recinte Hospital Joan March, Carretera Soller Km 12, 07110 Bunyola, Islas Baleares, Spain. E-mail: jbsoriano@caubet-cimera.es
}

both them and ourselves, as their messages will be promptly disseminated and the journal will maintain or even increase its profile and prestige [9]. The COPD research topics that would be most welcome by the ERJ editors are summarised in table 1 and are briefly covered in the following text by areas.

\section{DIAGNOSIS}

Ever since the early Ciba symposia, the diagnosis of obstructive respiratory diseases has been considered a challenge. This is mainly because of the overlap between asthma and COPD and the wide variability of lung function in the general population. In addition, the long-standing lack of lung function tests sensitive to abnormalities in small airways makes the diagnosis of COPD difficult in the early stages, when only the so-called "silent zone" of the lung is involved. Further research on the detection of early abnormalities by means of noninvasive (or minimally invasive) methods sensitive and/or specific enough to find early morphological changes in airways and/or lung parenchyma is badly required. The question of how to define COPD has been polarising researchers for decades, and it appears that new evidence separates further rather than produces nearer agreement. Advantages, disadvantages and quantification of the effectiveness of different definitions are to be researched. Beyond the endless argument on spirometry criteria, there is a need to determine which are the best functional and clinical predictors of individual and group morbidity/mortality, in order to find the best definition of the disease. In this context, monitoring of disease progression by lung function (and other domains) in relation to initial clinical or physiological characteristics and according to phenotypes will be welcome.

\section{EPIDEMIOLOGY}

Following the well-established public health principle, "to measure a health problem is the first step to identify a strategy to tackle it," the spread of the burden of COPD is, and will remain, a hot topic. More data on how frequent COPD is in low income (and middle and high income) countries with "blank" data of chronic lung disease are needed, as well as on the homogeneity of its distribution (or lack of it) in time and place, and all issues on comorbidities. Tobacco is the first and foremost causal risk factor for COPD, and perhaps it has been neglected too often in the past in many respiratory venues. We emphasise that we welcome submissions on key tobacco-related translational issues, and on the efficacy and the effectiveness of any smoking reduction and/or avoidance interventions, as well as on any other risk factors to help define it at the population and individual levels. Predicting the future is difficult, but more 


\begin{tabular}{|c|c|c|}
\hline Area & Topic & Question \\
\hline \multirow[t]{3}{*}{ Diagnosis } & Detection of early abnormalities & $\begin{array}{l}\text { Are there noninvasive (minimally invasive) methods to find early morphological changes } \\
\text { in airways, lung parenchyma, or both? }\end{array}$ \\
\hline & $\begin{array}{l}\text { Effectiveness of different definitions } \\
\text { and/or thresholds }\end{array}$ & $\begin{array}{l}\text { Beyond the endless argument on respiratory thresholds, is one definition better than others } \\
\text { for determining individual and group morbidity/mortality? }\end{array}$ \\
\hline & $\begin{array}{l}\text { Monitoring progression/decline in lung } \\
\text { function and other }\end{array}$ & $\begin{array}{l}\text { Are there lung function abnormalities predicting FEV1 decline? } \\
\text { Is the decline in lung function different depending on phenotype? } \\
\text { Can we develop new biomarkers to facilitate studies? }\end{array}$ \\
\hline \multirow[t]{2}{*}{ Epidemiology } & Spread of the burden of COPD & $\begin{array}{l}\text { How frequent is COPD in countries with "blank" data of chronic lung disease? } \\
\text { Is the COPD burden homogenous in time and place? }\end{array}$ \\
\hline & Risk factors and comorbidities & $\begin{array}{l}\text { Tobacco in COPD: how and when? } \\
\text { Anything else beyond tobacco? } \\
\text { Role of physical activity }\end{array}$ \\
\hline Basic science & Mechanisms, muscle and infection & $\begin{array}{l}\text { What are the mechanisms by which COPD manifests in only less than half of subjects } \\
\text { exposed to risk factors? } \\
\text { Why do some patients develop a bronchitic phenotype while others develop emphysema } \\
\text { or other? } \\
\text { What is the role of airway smooth muscle versus remodelling in different phenotypes? } \\
\text { What is the role of mucous hypersecretion in the pathogenesis of COPD? } \\
\text { What mechanisms underlie skeletal muscle dysfunction in COPD? }\end{array}$ \\
\hline Drugs and treatments & $\begin{array}{l}\text { Efficacy, safety and effectiveness of } \\
\text { current and new drugs }\end{array}$ & $\begin{array}{l}\text { How are responses to treatments in different phenotypes? } \\
\text { What are the effects of comorbidities on the response to different treatments? } \\
\text { Are outcomes in respiratory services the same in internal medicine or primary care? }\end{array}$ \\
\hline $\begin{array}{l}\text { Rehabilitation and other } \\
\text { non-drug interventions }\end{array}$ & $\begin{array}{l}\text { Efficacy, safety and effectiveness of } \\
\text { exercise training and noninvasive } \\
\text { ventilation }\end{array}$ & $\begin{array}{l}\text { Has exercise training long-lasting efficacy? Is it safe in all patients? } \\
\text { Rehabilitation in complex patients (CHF, obesity and ICU, etc.) } \\
\text { Pharmacological and nonpharmacological strategies to enhance rehabilitation outcomes } \\
\text { Home pulmonary rehabilitation and the role of education } \\
\text { Any nonconventional treatments producing objective, positive outcomes? } \\
\text { Anything else reducing exacerbations }\end{array}$ \\
\hline
\end{tabular}

FEV1: forced expiratory volume in $1 \mathrm{~s}$; CHF: congestive heart failure; ICU: intensive care unit.

national and international data to estimate the future COPD and tobacco burden are also welcome. The use of any lung function assessment, single or serial, alone or combined in multidimensional scores, aimed to screen, label and determine severity of COPD needs to be assessed with care.

\section{BASIC SCIENCE}

Even for the fully practising physician, dissemination of basic science research results is considered fundamental and formative. Thus, papers on mechanisms responsible for lung damage, susceptibility to infections and remodelling of the different components of lung architecture, and other are also welcome. Answers to what are the mechanisms by which COPD manifests in only less than half of subjects exposed to risk factors are desperately needed. An old term which is newly applied in COPD is phenotyping; that is, identifying different manifestations of the disease in individual patients. This can be done by clustering patients using both clinical and statistical criteria with measurements that are sensitive to different types/localisations of the underlying pathology. In terms of basic science, relevant questions need to be answered regarding why some patients develop predominantly small airway disease while others develop emphysema, and the role of distinct pathological traits in different clinical phenotypes (centrilobular versus panlobular emphysema), of airway smooth muscle versus whole airway remodelling and of mucous hypersecretion in the pathogenesis of COPD. Finally, the mechanism(s) underlying the development of abnormalities in organs other than the lungs are also of interest. Integration of basic science and all the "omics" data, with systems biology or other computer tools, holds potential in this field.

\section{DRUGS AND TREATMENTS}

Being a clinical journal, the ERJ welcomes papers on efficacy, safety and effectiveness of current and new drugs. Application of these drugs in all patients has been the target of several large clinical trials, which are welcomed by both respiratory and general journals. Studies looking at the effects of drug treatments in subsets of specific phenotypes are, however, lacking, and so are studies on the effects of comorbidities on the response to different treatments. This is a question that needs to be addressed if we want to know whether treatment outcomes are the same in respiratory services, internal medicine or primary 
care. In the end, both standard, randomised, double-blind trials in many hundreds or even thousands of "pure" COPD patients, and more "real life" pragmatic trials will be needed [10]. Last but not least, consider the ERJ when reporting on anything else reducing COPD exacerbations, from symptom-defined up to those requiring hospital admissions and their associated burden and costs.

When an investigator applies for funding, the main goal is to obtain money for conducting his/her research. Later, any potential author wants his/her research papers accepted in the best possible journal, and on time. We do hope that by guiding potential COPD authors to the ERJ, the benefit and gains are mutual. Journals can be considered as living entities. They indeed evolve with time and respond to change. Some become extinct. Survival of the fittest rules in the jungle of COPD research. Only by adapting to this new, more competitive environment in the struggle for the best COPD manuscripts will our beloved $E R J$ better serve our readers and the society.

\section{STATEMENT OF INTEREST}

A statement of interest for V. Brusasco can be found at www.erj. ersjournals.com/site/misc/statements.xhtml

\section{ACKNOWLEDGEMENTS}

We thank N. Ambrosino, M. Polkey and M. Saetta for their comments and input.

\section{REFERENCES}

1 Cazzola M, MacNee W, Martinez FJ, et al. Outcomes for COPD pharmacological trials: from lung function to biomarkers. Eur Respir J 2008; 31: 416-469.

2 European Respiratory Society/European Lung Foundation. European Lung White Book. Sheffield, European Respiratory Society Journals Ltd, 2003.

3 Bousquet J, Kiley J, Bateman ED, et al. Prioritised research agenda for prevention and control of chronic respiratory diseases. Eur Respir J 2010; 36: 995-1001.

4 Pinnock $\mathrm{H}$, Thomas $\mathrm{M}$, Tsiligianni I, et al. The International Primary Care Respiratory Group (IPCRG) Research Needs Statement 2010. Prim Care Respir J 2010; 19: Suppl. 1, S1-S20.

5 Agusti A, Barnes PJ. What the journal would like to publish on chronic obstructive pulmonary disease. Am J Respir Crit Care Med 2010; 182: 1-2.

6 Han MK, Agusti A, Calverley PM, et al. COPD phenotypes: the future of COPD. Am J Respir Crit Care Med 2010; 582: 598-604.

7 Dinh-Xuan AT, Brusasco V. Refining the changes. Or, how to modify the shape, not the spirit. Eur Respir J 2009; 34: 1.

8 Migliori GB, Soriano JB, Brusasco V, et al. ERJ peer reviewers: does this pillar of the Journal's quality need help? Eur Respir J 2011; 38: 251-252.

9 Brusasco V, Dinh-Xuan AT, Leff AR, et al. Impact factor and its role in academic promotion. Eur Respir J 2009; 34: 1499-1500.

10 Relton $\mathrm{C}$, Torgerson $\mathrm{D}, \mathrm{O}^{\prime}$ Cathain $\mathrm{A}$, et al. Rethinking pragmatic randomised controlled trials: introducing the "cohort multiple randomised controlled trial" design. BMJ 2010; 340: c1066. 